\title{
Managing quality in primary health care: the need for valid information about performance
}

Information about the quality of care is essential if quality is to be managed effectively, but information is difficult to come by in primary care. Systems for providing primary health care services vary from country to country. Depending on the country, the providers of care may be general practitioners, family physicians, specialists working in the community, or nurses. They may work in solo practices or in large, multi-professional groups or even teams, and may or may not be integrated with social and community services. They may or may not have a gatekeeper function to secondary care, and methods of funding primary health care vary from payment by the patient alone to payment by the state alone, with all manner of combinations between these extremes. It could be argued that the defining characteristic of national health care systems is the method of providing primary health care.

After years of neglect, governments and funding agencies in many countries have become interested in the potential of primary health care to slow the inexorable rise in expenditure on health care. But if this potential is to become a reality, primary health care services must be developed. In consequence, new training programmes for general practitioners have been established, national and international academies and associations have emerged, governments have increased investment in primary health care services, and new policies have been tried, to be replaced by further new policies when the original ones are found wanting. As primary care systems have become more complex, increasingly elaborate forms of management have become necessary. At the same time, concern among patients and policy makers about the quality of care has driven the development of policies for quality improvement. But in order to manage the quality of care, information is essential.

Several steps are required when measuring or monitoring the quality of care. Firstly, quality must be defined. Our definition may give greater or lesser importance to the different views of professionals, patients, or the funders of care. ${ }^{1}$ We may regard equity as more important than access, or efficiency as more important than relevance. Although the eventual choices inherent in defining quality are not usually made explicit, let us assume that we do have a definition. Specific and measurable indicators relating to that definition must then be selected. If we have adopted the health professional's definition of quality, the indicators should be based on best available research evidence about effectiveness. If we have adopted a patient's definition, we may prefer indicators about outcomes such as mortality rates, supplemented by information about the views of other patients. If we adopt a funder's definition, our indicators are more likely to reflect costs, numbers of cases treated, and outcomes.

Having selected our indicators, data are required. The data must be accessible, valid, complete, and relevant. Pri- mary care has a particular shortage of this type of data. The problems of measuring quality in primary health care are amply illustrated by a paper by McColl et al in this issue. ${ }^{2}$ The National Health Service in Britain was one of the first to begin the development of primary health care services and has now reached the fourth or fifth generation of policy reforms. Methods of management are relatively well developed and arrangements for quality improvement activities have been in place for almost a decade. Yet the collection of complete sets of data from 18 general practices about 26 indicators selected on the basis of good quality research evidence was far from easy. Remarkably, some computer systems were unable to retrieve data about relatively simple indicators.

If these problems exist in the relatively well organised service in the UK, they will be even more common in countries that have fragmented and underdeveloped primary care services. The problems are likely to increase even further if the definition of quality incorporates perspectives of patients and funders as well as professionals. If the core characteristic of primary care is the provision of personal and continuing care, the type of indicators required become even more complex.

What, then, must be done to enable measurement for management of quality in primary health care? A high priority must be improved recording systems. Suppliers of computer packages need encouragement to produce systems that are more adaptable and able to retrieve information more easily. Primary health care teams need help in obtaining skills to operate their computer systems. Teams must agree what data to record, and practitioners must enter data in a uniform manner. The indicators selected should be relevant to practitioners and patients, and therefore a wider variety of indicators is required. All this implies investment, accompanied by continued transformation of general practice delivered by the single handed provider to the integrated and tightly managed primary health care team. Whether patients will regard this as improvement remains to be seen. As services become more complex, management becomes more important, but as services increase in size and complexity, they become less satisfying to the user. This is the Catch 22 for primary health care.

RICHARD BAKER

Clinical Governance Research and Development Unit,

Department of General Practice and Primary Health Care,

University of Leicester,

Leicester General Hospital,

Leicester LE5 4PW,

UK

rb14@le.ac.uk

1 Donabedian A. Explorations in quality assessment and monitoring. Volume 1. The definition of quality and approaches to its assessment. Ann Arbor: Health Administration Press, 1980.

2 McColl A, Roderick P, Smith H, et al. Clinical governance in primary care groups: the feasibility of deriving evidence-based performance indicators. Quality in Health Care 2000;9:90-7. 